\title{
Parental Influence on Children's Computational Thinking in an Informal Set- ting (Fundamental Research)
}

\section{Mr. Carson Ohland, Purdue University, West Lafayette}

Undergraduate Student in Aeronautical \& Astronautical Engineering at Purdue University

\section{Ms. Hoda Ehsan, Purdue University, West Lafayette}

Hoda is a Ph.D. student in the School of Engineering Education, Purdue. She received her B.S. in mechanical engineering in Iran, and obtained her M.S. in Childhood Education and New York teaching certification from City College of New York (CUNY-CCNY). She is now a graduate research assistant on $\mathrm{STEM}+\mathrm{C}$ project. Her research interests include designing informal setting for engineering learning, and promoting engineering thinking in differently abled students in informal and formal settings.

\section{Dr. Monica E. Cardella, Purdue University, West Lafayette}

Monica E. Cardella is the Director of the INSPIRE Research Institute for Pre-College Engineering and is an Associate Professor of Engineering Education at Purdue University. 


\title{
Title: Parental Influence on Children's Computational Thinking in an Informal Setting (Fundamental Research)
}

\begin{abstract}
Informal learning environments such as science centers and museums are instrumental in the promotion of science, technology, engineering, and mathematics (STEM) education. These settings provide children with the chance to engage in self-directed activities that can create lifelong interest and persistence in STEM. In addition, the participation of parents in these settings can engage children in conversations that can boost understanding and enhance learning of STEM topics. To date, a considerable amount of research has focused on adult-child dialogue. Findings from those studies revealed that children experience more elaborate scientific thinking when parents facilitate learning.
\end{abstract}

Given the need for engineers to have computer science skills, academic discourse has placed emphasis on studying computational thinking (CT) in children. While some recent studies have focused on the roles parents play to promote children's engineering thinking, very few studies have explored parents' influence on children's engagement in CT. Therefore, in this study, we investigate the roles that parents play in promoting computational thinking in their young children.

In this study, families of 5-7 year-old children were invited to a science center. The families were asked to interact with an exhibit, "Computing for the Critters," that was designed to promote engineering and computational thinking in children. We conducted a qualitative case study to closely examine child-parent interactions during one portion of the exhibit that is a computerbased coding game. Drawing on previous literature from engineering education and informal science education, a coding scheme was developed with the essential roles that parents play in science centers and museums. The roles include Supervising, Co-learning, Facilitating, Encouragement and Student of the Child. In this study, we have observed that parents take multiple roles in which some of them resulted in children's enactment of CTs. The findings of this study advance our understanding of how parents can support computational thinking while engaging in conversations during engineering activities.

\section{Introduction}

Previous research has established that there are many reasons pre-college engineering education is important. Children naturally tend to engage in engineering behaviors like asking questions, explaining cause and effect activities, constructing knowledge, and solving problems [1]. However, research has shown that undergraduate engineering students engage in limited information gathering while working on engineering design tasks [2], suggesting that they may need to 'relearn' the question asking they naturally engaged in as children. At the same time, interest in engineering at the undergraduate level is often fostered through childhood participation in engineering activities. Some argue that by the time children reach middle school, their interests and perceptions towards their future careers are established [3]. Therefore, when children lack access to opportunities to learn about engineering in pre-college settings, this results in limited understanding about engineering and underdeveloped engineering skills. It can also limit interest in pursuing engineering careers, and ability to see oneself as able to engage in engineering. 
One way to increase children's engineering interest and engagement is to provide out-of-school opportunities for them. Children spend most of their waking hours out of school [28] and particularly for children under the age of 10, parents have the most control of those hours. Outof-school learning environments can have a positive and permanent influence on significant cognitive growth in students [4]. In response, many researchers, educators and stakeholders have developed summer and afterschool programs, toys, games and apps, and museum exhibits to help children learn about engineering. However, while there is a research basis for the value of out-ofschool learning environments in general, there is limited research that characterizes the engineering thinking of children in out-of-school settings and how these venues can promote engineering thinking of children.

Out-of-school settings like museums provide opportunities for self-directed and intrinsicallymotivated learning and engagement for children [5]. Children's STEM (Science, Technology, Engineering and Math) learning and engagement may be further improved by parent involvement. When parents accompany their children during their visit to STEM museums, children are more attentive to exhibits, are engaged in more open-ended and sense-making conversations $[6,7]$ over longer time frames and can develop more scientific thinking [5]. A small number of research studies have explored the ways that parents can help improve children's engineering thinking and skills [e.g. 8-12]. For example, in a recent study, Svarovsky and colleagues examined parent-child conversations to investigate how parents can facilitate engineering design practices in the context of short design activities [11]. The research on parents' roles in facilitating children's engagement in other skill sets and knowledge bases related to engineering, such as computational thinking (CT), is even more limited. In our own work, in another study we explored the roles of parents in engaging children in computational thinking (CT) during an engineering design activity [12]. However, we are not aware of other studies which have explored parental roles in children's CT enactments. At this point, then, we might ask: why is it important to understand how parents can help children engage in computational thinking?

\section{Computational Thinking}

Given the growth of technology, the demands for employees with programming and computing skills have increased. Looking at the engineering workforce, many engineers are required to work with computing software. Many engineers are engaged in using and creating technologies that involve computing. From a curricular standpoint, undergraduate engineering students frequently learn programming and coding skills to use tools such as MATLAB in their work. As a result, we can expect that many current K-12 students will end up working in fields that involve programming and computing [13]. Therefore, for children to prepare for future success in a technologically advanced society, they need to gain skills and thinking competencies related to computing.

Computational thinking $(\mathrm{CT})$, like engineering thinking, is a problem-solving process that is more than, but required for, programing and coding [14]. CT is not thinking like computers, but is a way that "humans, not computers, think" [14, p:35]. CT is embedded in activities across a variety of disciplines. CT is associated with competencies and concepts that are needed to conceptualize problems across multiple fields as well as everyday activities $[13,14]$. Different frameworks and models have identified and defined these competencies differently, but 
commonly include understanding, defining and reformulating problems, thinking at multiple levels of abstractions, parallel processing and using strategies to work with data [15].

Many believe that CT and engineering are connected and empower each other [16]-[14]. Cunningham, in an NRC report on $\mathrm{CT}$, states that engineering is a focus of CT for elementary education [16]. Students can engage in computational thinking in the context of engineering education due to the overlap of engineering and computational thinking. Shute, Sun and AsbellClarke [17] recognize overlap between CT and engineering where both have a focus on 'problem solving, along with understanding how complex systems work in the real world. [p: 146] Wing [14] connects computational thinking to engineering thinking by arguing that computational thinking is the overlap between engineering thinking and mathematical thinking. As a result of the strong connection between these two types of thinking, and the prevalence of CT and programming in engineering in professional practice, we believe that exploring CT is an important aspect of learning about children's engineering learning.

\section{Purpose of the study}

This study is part of an NSF-funded project that integrates computational thinking in STEM activities and curriculums both in formal and informal settings. The aim of the project is to characterize children's computational thinking in different learning settings. Consistent with the aim of the project, we have previously explored the evidence of computational thinking exhibited by K-2 aged children during their family visit to a science center and their interaction with a computational thinking exhibit [18]. Building on that study, the goal of this study is to explore the roles that parents play during CT family-based activities. We are specifically focusing on one section of the exhibit which is a computer-based coding game. The overarching research question that we answer in this study is:

What roles do parents play when their children are solving problems during a computer-based coding game activity? And to what extent does each role lead to children's engagement in computational thinking?

We answer this question using two frameworks. The first model is a CT framework that our research team has developed and was used and validated in previous studies both in formal and informal learning setting [19-21]. The second framework captures parental roles. We have developed this framework by reviewing literature on the roles that parents play in promoting STEM skills and concepts in their children during informal learning experiences. Both frameworks are further discussed in the section below.

\section{Computational Thinking Framework}

Computational thinking (CT) is a cognitive process that consists of several concepts and competencies that can help in solving problems. As mentioned before, many models for CT exist but mostly target older children or they have not specified the age level. As a result, these models have identified, defined and/or described these competencies or concepts differently. For example, BBC education [22] introduces 11 to 14 year-olds to CT by defining and describing four key competencies: Abstraction, Algorithm, Decomposition and Pattern Recognition. Similarly, the Australian Curriculum, Assessment and Reporting Authority [23] identified five competencies for CT: Abstraction, Algorithm, Data Analysis, Decomposition and Simulation. 
However, the CT model of Google for Education and the Computational Science Teacher Association (CSTA) associate more competencies with CT. Google for Education [24] named 11 competencies and called them "mental processes" which include Abstraction, Algorithm Design, Automation, Data Analysis, Data Collection, Data Representation, Decomposition, Parallelization, Pattern Generalization, Pattern Recognition and Simulation. The CSTA [25] identify Abstraction, Algorithms and Procedures, Automation, Data Analysis, Data Collection, Data Representation, Parallelization, Problem Decomposition and Simulation.

In this study, we utilize a CT framework that is similar to the Google for Education model, with modifications and additions. This framework has been developed after summarizing and synthesizing several models which covered all range of ages. We have found Google's competencies and their definitions similar to the initial evidence we observed of children's CT enactment. Therefore, informed by the synthesis of CT models, we modified the definitions and added additional information to make the competencies more applicable to our target group. Through this framework, we have operationalized CT competencies in both formal and informal education contexts. The findings of our previous studies confirmed that children are capable of engaging in these competencies [e.g. 18,19,20]. As a result, we believe that the framework can be broadly used for teaching and conducting research for children (K-2 aged). Table 1 illustrates this CT framework.

Table 1 Computational Thinking Framework for Children

\begin{tabular}{|l|l|}
\hline CT Competency & INSPIRE Definitions \\
\hline Abstraction & $\begin{array}{l}\text { Identifying and utilizing the structure of concepts/main } \\
\text { ideas }\end{array}$ \\
\hline Algorithms and Procedures & $\begin{array}{l}\text { Following, identifying, using, and creating an ordered set } \\
\text { of instructions (i.e., through selection, iteration and } \\
\text { recursion) }\end{array}$ \\
\hline Automation & $\begin{array}{l}\text { Assigning appropriate set of tasks to be done repetitively } \\
\text { by computers }\end{array}$ \\
\hline Data Collection & Gathering information pertinent to solve a problem \\
\hline Data Analysis & Making sense of data by identifying trends \\
\hline
\end{tabular}




\begin{tabular}{|l|l|} 
Data Representation & $\begin{array}{l}\text { Organizing and depicting data in appropriate ways to } \\
\text { demonstrate relationships among data points via } \\
\text { representations such as graphs, charts, words or images }\end{array}$ \\
\hline Debugging/Troubleshooting & $\begin{array}{l}\text { Identifying and addressing problems that inhibit progress } \\
\text { toward task completion }\end{array}$ \\
\hline Problem Decomposition & $\begin{array}{l}\text { Breaking down data, processes or problems into smaller } \\
\text { and more manageable components to solve a problem }\end{array}$ \\
\hline Parallelization & $\begin{array}{l}\text { Simultaneously processing smaller tasks to more } \\
\text { efficiently reach a goal }\end{array}$ \\
\hline Simulations & $\begin{array}{l}\text { Developing a model or a representation to imitate natural } \\
\text { and artificial processes }\end{array}$ \\
\hline Pattern Recognition & $\begin{array}{l}\text { Observing patterns, trends and regularities in data } \\
\text { (Google) }\end{array}$ \\
\hline
\end{tabular}

\section{Parental Role Framework}

The theoretical framework for the parental roles was created based on our synthesis of roles and methods of engagement defined by other studies $[5,11,26]$. These varied roles and interactions were considered and combined to best fit the interactions observed in the data. In addition to these roles, an emergent role, Disengagement, was defined after observing parental interactions during the activity which were not adequately described by any of the roles from the literature.

Table 2: Parental Role Framework

\begin{tabular}{|l|l|l|l|}
\hline Role & Leader & Definition & $\begin{array}{l}\text { Examples form the } \\
\text { Current Study }\end{array}$ \\
\hline $\begin{array}{l}\text { Supervising / } \\
\text { Directing } \\
{[5],[11],[26]}\end{array}$ & Most Adult-led & $\begin{array}{l}\text { Parent directly } \\
\text { instructs child to act } \\
\text { in a specific way. }\end{array}$ & $\begin{array}{l}\text { "You guys do the } \\
\text { same path in there. So } \\
\text { you've gotta go to } \\
\text { your right" }\end{array}$ \\
\hline Facilitation [11], [26] & Adult-Led & $\begin{array}{l}\text { Parent makes } \\
\text { suggestions and }\end{array}$ & $\begin{array}{l}\text { "Do you not think } \\
\text { that would have been }\end{array}$ \\
\hline
\end{tabular}




\begin{tabular}{|l|l|l|l|}
\hline & & $\begin{array}{l}\text { prompts the child to } \\
\text { think in a specific } \\
\text { way. }\end{array}$ & $\begin{array}{l}\text { quicker if you went to } \\
\text { red first?" }\end{array}$ \\
\hline Co-learning [26] & No leader & $\begin{array}{l}\text { Both parent and child } \\
\text { work together on a } \\
\text { task together; neither } \\
\text { is the leader and no } \\
\text { prompting occurs. } \\
\text { Parent and child share } \\
\text { information with each } \\
\text { other. }\end{array}$ & $\begin{array}{l}\text { Parent shows the } \\
\text { current location of the } \\
\text { robot in the game } \\
\text { while the child enters } \\
\text { "'Onstructions }\end{array}$ \\
\hline $\begin{array}{l}\text { Student of the Child } \\
\text { [11],[26] }\end{array}$ & Child-led & $\begin{array}{l}\text { Parent prompts the } \\
\text { child to take the lead } \\
\text { in the activity, where } \\
\text { the parent acts as a } \\
\text { student. }\end{array}$ & $\begin{array}{l}\text { "So we know that you } \\
\text { got the cat. Now } \\
\text { what?" }\end{array}$ \\
\hline Disengagement & Most Child-led & $\begin{array}{l}\text { The parent } \\
\text { completely } \\
\text { disengages from the } \\
\text { activity, leaving the } \\
\text { child to continue on } \\
\text { their own. }\end{array}$ & $\begin{array}{l}\text { Parent reassures or } \\
\text { encourages the child } \\
\text { while they are } \\
\text { working on a task or } \\
\text { after they complete a } \\
\text { task. }\end{array}$ \\
\hline Encouragement [26] & Ancillary & $\begin{array}{l}\text { "Ywesteps back" } \\
\text { answer" }\end{array}$ \\
\hline
\end{tabular}

\section{Methods}

In this study, we collected video-recordings and conducted a qualitative analysis of the videos to explore the roles that parents play to promote CT in their children. We focused on child-adult interactions while child-adult dyads engaged with the computer-based coding activity. The setting is the science center and the context is the computer-based coding game. Parental support of CT learning is an understudied area and required a deep exploration; therefore, we utilized an exploratory inductive-deductive coding approach with a subset of our data. Since no a priori codebook existed, a codebook was developed based on roles identified in the previous studies with similar cases (child-adult) in similar settings. In this exploratory study, we will explore if these roles are applicable to this context and if other roles are emerged.

\section{Data Collection}

This study was conducted at a small science center and is a subset of a larger project which is examining how children engage in computational thinking in formal and informal settings [33] . While several different types of data were collected for this project, for this study we focused on video data of six families. The structure of the families consists of female parents and one K2 aged child. For this study, we selected these families because the parents were highly engaged 
for most of the activity. The decision to limit the cases to those with high parental involvement was made to ensure that the subset of cases produced sufficient data for analysis. To fully capture the child-parent interactions, families were video recorded using two cameras with different angels, and the length of each video varies between 5-20 minutes.

\section{Data Analysis}

To analyze the impact of parental involvement on children's computational thinking, we used existing narratives of the video data which were previously coded for computational thinking competencies and then re-coded the narratives with respect to the defined parental roles. Where we found the narratives unclear, we re-watched the videos and recoded for both CT and the parental roles. Half of the cases were coded by two researchers to establish inter-coder reliability. The generated codes for parental roles were compared with the established codes for children's computational thinking competency use to analyze their correlation, especially when a parental role code was closely followed by or (meaningfully resulted in) a child's CT enactment. To have a more analytical and interpretive lens, we have quantified our findings; meaning that we counted the frequency of the instances parents played a certain role, and the number of those that resulted in children's CT engagement. We compiled the findings into a summary statistics table for the two variables-(parent's roles and child's CT enactment) (see Table 3). To further explore potential patterns of relationships among the variables, we conducted a percentage value of total and effective roles. To be clear, this percentage value are only meant to further understand the qualitative patterns in coded data. They are not intended to be broadly generalizable and predictive.

\section{Findings and Discussion}

In this study we aimed to examine the roles that parents play when they and their children are interacting with a computer-based coding game. We have observed that parents took multiple roles during the activity and that some resulted in children's computational thinking enactments. Table 3 illustrates the the summary statistics of the parental roles that resulted in child's CT engagement. In this section, we also describe the roles and ways the roles led to children's CT engagement.

Table 3: Parental Role Used and Child's Computational Thinking Response

\begin{tabular}{|c|c|c|c|c|c|c|}
\hline Role & $\begin{array}{l}\text { Supervising } \\
\text { / Directing }\end{array}$ & $\begin{array}{l}\text { Facilitati } \\
\text { on }\end{array}$ & $\begin{array}{l}\text { Co- } \\
\text { learning }\end{array}$ & $\begin{array}{l}\text { Student } \\
\text { of the } \\
\text { Child }\end{array}$ & $\begin{array}{l}\text { Disengageme } \\
\text { nt }\end{array}$ & $\begin{array}{l}\text { Encouragemen } \\
t\end{array}$ \\
\hline $\begin{array}{l}\text { Total } \\
\text { instances of } \\
\text { role use }\end{array}$ & 27 & 30 & 23 & 7 & 7 & 3 \\
\hline \multicolumn{7}{|c|}{ CT competency as a result of the parental roles } \\
\hline Abstraction & 0 & 1 & 2 & 1 & 0 & 0 \\
\hline $\begin{array}{l}\text { Algorithm and } \\
\text { Procedure }\end{array}$ & 9 & 6 & 8 & 0 & 5 & 0 \\
\hline
\end{tabular}




\begin{tabular}{|l|l|l|l|l|l|l|}
\hline $\begin{array}{l}\text { Data } \\
\text { Collection }\end{array}$ & 1 & 1 & 0 & 0 & 0 & 0 \\
\hline $\begin{array}{l}\text { Debugging / } \\
\text { Troubleshooti } \\
\text { ng }\end{array}$ & 5 & 10 & 3 & 4 & 0 & 0 \\
\hline $\begin{array}{l}\text { Problem } \\
\text { Decompositio } \\
\text { n }\end{array}$ & 0 & 0 & 1 & 1 & 0 & 0 \\
\hline Parallelization & 0 & 0 & 1 & 1 & 0 & 0 \\
\hline Simulations & 1 & 3 & 2 & 0 & 0 & 0 \\
\hline $\begin{array}{l}\text { Pattern } \\
\text { Recognition }\end{array}$ & 0 & 1 & 2 & 0 & 0 & 0 \\
\hline $\begin{array}{l}\text { Percentage of } \\
\text { the instances } \\
\text { of this role } \\
\text { that led to } \\
\text { child's CT }\end{array}$ & $59 \%$ & $73 \%$ & $83 \%$ & $100.00 \%$ & $71 \%$ & $0.00 \%$ \\
\hline
\end{tabular}

\section{Supervising / Directing}

Parents use the Supervising/Directing role in a multitude of situations. Commonly, parents use Supervising / Directing to fill in gaps in their children's knowledge. If, for example, the child has not or cannot read the instructions, the parent may directly tell the child what to do until the child grasps the task at hand. In other cases, a parent may become frustrated or impatient if a child fails to solve a problem quickly, and may resort to taking full control of the activity. Sometimes, this role is not even used to further progress in the activity. In this case, a parent may use Supervising / Directing to keep a child from getting distracted or misbehaving. Naturally, some of these cases are unlikely to help the child engage in computational thinking, especially when this role is used to control a child in a way that is unrelated to the activity.

Across all uses of Supervising / Directing, as highlighted in Table 3, use of the role correlates with CT competency engagement by children close to $60 \%$ of the time. Even when children engage in CT competencies as a result of Supervision / Direction by a parent, they are not likely to engage in the competencies in a meaningful way. For example, when a parent prompts a child to use the Algorithm / Procedure competency utilising this role, they generally do so by listing a set of moves for the child to enter in to the game by rote. Here it is possible that the child takes no part in generating the algorithm; but they mindlessly enter a sequence of instructions fed to them by the parent. Certainly, following a procedure given by a parent is a less significant CT engagement for a child than actively participating in the generation of a procedure. This issue with Supervising / Directing is mirrored in several other CT competencies. In debugging, for example, parents who are Supervising / Directing tell a child exactly what moves have caused the robot to hit a wall, allowing the child to delete moves to that point and continue, instead of allowing the child to go through a process of determining the cause of the error and generating a solution. 


\section{Facilitation}

Facilitation is the most frequently used role in our six cases. Parents generally use Facilitation to reduce the challenge of the task or to help nudge their child towards a conclusion they may have overlooked. In Facilitation, the parent retains control of the activity, but, in contrast to Supervising / Directing, the child is still free to act independently. Since Facilitation is used by parents to help children engage in higher-level thinking, it is no surprise that it is highly correlated with children's CT engagement. For the cases in this study, Facilitation use by parents was followed by CT engagement by their children about $3 / 4$ of the time. In the computer game, parents most commonly use Facilitation to help their children debug entered code. In contrast to Supervising / Directing, in Facilitation, parents only give the child some of the necessary information on how to fix the problem. Generally, parents tell the child the location of the error in the code after the child discovers that an error exists (after running the code and seeing it fail). Sometimes, however, the parent may hint to the child that they have made a mistake using phrases like "Do you want to check that again?" In these cases, children engage more fully in competencies than they would if their parent simply commanded them, as in Supervising / Directing. Additionally, in some cases Facilitation may enable a child to solve a problem that they otherwise would not be able to. However, children engaging in competencies as a result of Facilitation still may not engage as deeply in the competencies as they do when they lead the interaction or engage independently of their parents, as in the roles that follow.

\section{Co-learning}

Co-learning, while infrequently used, can be very valuable to children's CT enactment. Parents use Co-learning similarly to Facilitation, but in Co-learning parents do not prompt their children to think in a certain way. Instead, parents share information and assist their children with the task at hand, but leave decisions and the flow of the activity up to the child. In the video game, the most common use of Co-learning sees parents placing their fingers on the screen at the robot's location at the child's current position in the code. Parents usually begin using this strategy if they see that their child is struggling to keep track of the robot's location in space. The parent's assistance reduces the stress and difficulty of the task for the child, but the child is still able to generate their own algorithm to solve the level. This is the reverse case of algorithm in Supervising / Directing, and it allows the parent to remain engaged in the activity and to help reduce the challenge for the child without getting in the way of the child's CT engagement. Parents' use of Co-learning is followed by children's engagement in CT competency about $4 / 5$ of the time in our data, however these numbers are naturally inflated compared to the other roles since Co-learning is used almost exclusively in the scenario described previously, when the child is already engaging in Algorithm / Procedure.

\section{Student of the Child}

Parents do not utilize the Student of the Child role very frequently, as is clear from Table 3. Although only a few (7) instances of this role were observed across all six cases, it seems clear that use of the Student of the Child role is highly correlated with children's computational thinking. Parents use Student of the Child when they ask broad questions and allow children to take charge of the approach to the task. Such questions are "what do you think we should do now?" and "how do you think we should do this?" When a child engages in a competency as a result of their parent using the Student of the Child role, they must engage organically and on a broader level than they do with any other role, since their parent encourages them to think about 
the problem as a whole and to go through the problem solving process, instead of prompting them to engage in particular competencies on the path towards solving the problem.

\section{Disengagement}

Most parents in our test group did not disengage at all during the activity; in fact, all seven instances of Disengagement occured in the same case. After the parent disengaged, the child remained engaged in the activity and continued to engage in the competencies necessary for its completion. Unfortunately, the child began to generate sub-optimal solutions to problems than they would with help from their parents. Additionally, in the case where the parent disengaged, the child became increasingly distressed the longer they worked on the problem alone, frequently looking to their parent for validation of their solutions and choices. The distress was seen even when the child was successful in completing a level on their own. This result is consistent with prior research, which has shown that parents' decision to continue or abandon an activity can influence their child's inclination to the same [27]

\section{Encouragement}

Encouragement was not captured very frequently; however it does not seem to directly influence children's computational thinking. It may, however, be important to children's engagement in computational thinking and STEM activities. As discussed previously, children may become distressed if their parent does not engage in the activity with them, encouraging them directly or indirectly to continue.

\section{Conclusion and Implications}

In this study, we have explored the roles that parents played during a family-based computational thinking activity. During this activity, we have observed parents playing different roles in different situations and many of them fostered children's CT. This study adds to literature on engineering and computer science education as it provides insights into the productive roles and strategies that parents can take to promote computational thinking of their children. We believe that while various parental roles resulted in children's CT enactments, the thinking and cognitive level children engaged in was different. The findings of this study highlight the importance of allowing children to lead a computing activity and independently engage in tasks, while providing enough support and scaffolding to reduce the challenges and pressure that children may face. For example, as was observed in family cases, Supervising / Directing resulted in computational thinking of children; however, it did not necessarily foster higher order Debugging and Algorithm. In addition, we believe both children's engagement in CT and the roles parents play can be dependent on the nature of the activities. As an example, given the nature of the computer-based coding activity, the child is very likely to engage in Algorithm and Procedure by entering a set of instructions (an algorithm) for a robot, and then Debugging/Troubleshooting to fix the instructions. Therefore, these competencies are more likely to be promoted through parents' roles than any other competencies.

While in this study, we have only focused on six family cases, we believe the findings are not limited to this population and can be applicable to other children in different settings. However, in future studies, we will explore parental influences on children's CT engagement during computing activities with different structures in various formal and informal settings. We also see the need to further explore the ways that children engage in different computational thinking 
competencies as a result of parents' roles. It is important to know to what extent children are able to independently engage in higher level of computational thinking competencies.

As we extend this study to more cases in different settings and activities, one implication of this study is to educate parents on how to engage their children in computational thinking. For example, as this work is extended in a future study that is more quantitative in nature, if we continue to see few uses of the Student of the Child role from parents, it will be important to consider how we might promote more use of this role. Perhaps future exhibit signage could present parents with information about the six different roles that they might play, as well as examples of what this might look like in the context of CT activities. Additionally, we might consider other opportunities for parent education-- particularly as CT is often new to parents just as it is new for their children.

\section{References}

[1] Bairaktarova, D., Evangelou, D., Bagiati, A., \& Brophy, S. (2011). Early engineering in young children's exploratory play with tangible materials. Children Youth and

Environments, 21(2), 212-235.

[2] Atman, C. J., Adams, R. S., Cardella, M. E., Turns, J., Mosborg, S., \& Saleem, J. (2007).

Engineering design processes: A comparison of students and expert practitioners. Journal of engineering education, 96(4), 359-379.

[3] Ceci, S. J., \& Williams, W. M. (2010). Sex differences in math-intensive fields. Current Directions in Psychological Science, 19(5), 275-279.

[4] Hofstein, A., \& Rosenfeld, S. (1996). Bridging the gap between formal and informal science learning. Studies in Social Science Education, 28(1996) 87-112.

[5] K. Crowley, M. A. Callanan, J. L. Jipson, J. Galco, K. Topping, and J. Shranger. "Shared scientific thinking in everyday parent-child activity," Science Education, vol. 85, no. 6, 2001.

[6] K. Crowley and M. Jacobs, "Building Islands of Expertise in Everyday Family Activity," Learning Conversations in Museums, vol. 33356, 2002.

[7] H. T. Zimmerman, S. Reeve, and P. Bell, "Family sense-making practices in science center conversations," Science Education, vol. 91, no. 5, 2010.

[8] B. L. Dorie, M. E. Cardella, and G. N. Svarovsky, "Capturing the engineering behaviors of young children interacting with a parent," in Proceedings of the 2014 ASEE Annual Conference and Exposition Indianapolis, IN, June 2014.

[9] M. E. Cardella, G. N. Svarovsky, B. L. Dorie, Z. Tranby, and S. V. Cleave, "ender Research on Adult-child Discussions within Informal Engineering Environments (GRADIENT): Early Findings.," in Proceedings of the 2013 ASEE Annual Conference and Exposition, Atlanta, GA, June 2013.

[10] C. A. Haden, E. A. Jant, P. C. Hoffman, M. Marcus, J. R. Geddes, and S. Gaskins, "Supporting Family Conversations and Children's STEM Learning in a Children's Museum," Early Childhood Research Quarterly, vol. 29, no. 3, 2014.

[11] G. N. Svarovsky, M. E. Cardella, B. Dorie, and Z. King, "Productive Forms of Facilitation for Young Girls During Engineering Activities Within Informal Learning Settings," in Proceedings of the 2017 Annual American Educational Research Association Meeting, San Antonio, TX, May 2017.

[12] H. Ehsan, T. Dandridge, and M. Cardella, "Parental Influences in Computational Thinking of Children During an Engineering Design Task," in 31st Annual Visitor Studies Association Conference, Chicago, IL, 2018. 
[13] V. Barr, C. Stephenson, and B. V. Barr, "Bringing Computational Thinking to K-12: What is Involved and What is The Role of the Computer Science Education Community?" ACM Inroads, vol. 2, no. 1, 2011.

[14] J. M. Wing, "Computational Thinking," Communications of the ACM, vol. 49, no. 3., 2006.

[15] J. Cuny, L. Snyder, and J. M. Wing, "Demystifying Computational Thinking for NonComputer Scientists," Unpublished. Manuscript, 2010

[16] National Research Council, Report of a Workshop on the Pedagogical Aspects of Computational Thinking. Washington, D.C.: The National Academies Press, 2011.

[17] V. J. Shute, C. Sun, and J. Asbell-Clarke, "Demystifying computational thinking," Educational Research Review. 2017.

[18] H. Ehsan, C. Ohland, T. Dandridge, and M. Cardella, "Computing for the Critters: Exploring Computational Thinking of Children in an Informal Learning Setting." In 2018 IEEE Frontiers in Education Conference (FIE), San Jose, CA, October 2018.

[19] H. Ehsan, and M. Cardella, "Capturing the Computational Thinking of Families with Young Children in Out-of-School Environments." 124th ASEE Annual Conference \& Exposition, June 25-28. Columbus, Ohio. 2017

[20] A. Dasgupta, A. Rynearson, S. Purzer, H. Ehsan, \& M. Cardella, "Computational Thinking in Kindergarten: Evidence from Student Artifacts (Fundamental)" 124th ASEE Annual Conference \& Exposition, June 25-28. Columbus, Ohio. 2017

[21] H. Ehsan, T. Dandridge, I. Yeter, and M. Cardella,. "K-2 Students' Computational Thinking Engagement in Formal and Informal Learning Settings: A Case Study (Fundamental). 125th ASEE

Annual Conference \& Exposition, June 25-28. Salt Lake City , UT. 2018

[22] BBC [Online]. Bitesize. Retrieved from https://www.bbc.com/education/topics/z7tp34j.

[23] Australian Curriculum, Assessment and Reporting Authority (2015). Report of the Australian Curriculum Technologies. Retrieved from, http://www.acara.edu.au.

[24] Google [Online]. Computational Thinking Concepts Guide. Retrieved, Jan 4, 2019, from https://docs.google.com/document/d/1i0wg-

BMG3TdwsShAyH_0Z1xpFnpVcMvpYJceHGWex_c/edit.

[25] Computer Science Teacher Association (CSTA) and International Society for Technology in Education (ISTE), Computational thinking teacher resources, 2nd ed. 2011.

[26] Beaumont, L. (2010). Developing the adult child interaction inventory: A methodological study. Unpublished manuscript, The Boston Children's Museum, Boston, MA.

[27] Svarovsky, G. N., Wagner, C., \& Cardella, M. E. (2018). Exploring Moments of Agency for Girls during an Engineering Activity. International Journal of Education in Mathematics, Science and Technology, 6(3), 302-319.

[28] National Research Council. Learning science in informal environments: People, places, and pursuits. National Academies Press, 2009.

[29] J. Case and G. Light, "Emerging research methodologies in engineering education research," J. Eng. Educ., 2011.

[30] C. G. Schnittka, "Engineering education in the science classroom: A case study of one teacher's disparate approach with ability-tracked classrooms," J. Pre-College Eng. Educ. Res., 2012.

[31] J. M. Scolnic, K. Spencer, and M. Portsmore, "Viewing student engineering through the lens of 'engineering moments': An interpretive case study of 7th grade students with language-based learning disabilities," in 121st ASEE Annual Conference \& Exposition, 2014. 
[32] M. A. Corey. E. A. Siverling, A. W. Glancy, S. Selcen Guzey, and T. J. Moore. "Students' use of evidence-based reasoning in K-12 engineering: A case study (fundamental)." in 123rd ASEE Annual Conference and Exposition, 2016.

[33] M. M. Hynes, T. J. Moore, M. E. Cardella, K. Tank, S. Purzer, M. Menekse, S. Brophy, H. Ehsan and I. Yeter, "Inspiring Young Children to Engage in Computational Thinking In and Out of School (Research to Practice)." $126^{\text {th }}$ ASEE Annual Conference \& Exposition, June 15-18. Tampa, Fl. 2019 